\title{
AVALIAÇÃO DA SENSIBILIDADE DE ZIGOTOS MURINOS A BRUCELLA ABORTUS PARA O ESTABELECIMENTO DE UM MODELO EXPERIMENTAL EM ESTUDOS DE INTERAÇÕES EMBRIÕES-PATÓGENOS
}

\section{A.G. Galuppo, M. D’Angelo, S. Miyashiro, E. Scarcelli, M.L.P. Senedezi, G.M. Melo, R.J. Souza}

Instituto Biológico, Centro de Pesquisa e Desenvolvimento de Sanidade Animal, Av. Cons. Rodrigues Alves, 1252, CEP 04014-002, São Paulo, SP, Brasil. E-mail: andreagalupo@yahoo.com.br

\section{RESUMO}

\begin{abstract}
O objetivo desse trabalho foi avaliar in vitro a sensibilidade de zigotos murinos à Brucella abortus, a fim de estabelecer um modelo acessível para o estudo de interações embriões-patógenos. Para a coleta dos zigotos, foram utilizados camundongos fêmeas (Swiss Webster) acasaladas com machos inteiros, após superestimulação ovariana. Para a infecção foi utilizada a bactéria B.abortus 1119.3 e a suspensão foi preparada no momento da inoculação (diluição de $10^{6}$ bactérias $/ \mathrm{mL}$ ). Os zigotos foram separados em controle e infectados ( $30 \mu \mathrm{L}$ da suspensão de bactérias), e após 24 e $96 \mathrm{~h}$ foram analisados quanto à morfologia e taxa de clivagem. No grupo controle não foram verificadas alterações morfológicas, já no infectado foi possível verificar a presença de blastômeros irregulares, falha de divisão, citoplasma com granulação e aspecto degenerativo. As taxas declivagem após $24 \mathrm{~h}$ foram de $77,4 \%$ (controle) e 59,2\% (infectados) $\left(\chi^{2}\right.$ de 0,001674; p < 0,05) e após 96 h de infecção 14,5\% (controle) e $7 \%$ (infectados) $\left(\chi^{2}\right.$ de 0,$\left.141616 ; p<0,05\right)$. Considerando os resultados pode-se concluir que os zigotos murinos são sensíveis à $B$. abortus após exposiçãoinvitro. Provavelmente os zigotos murinos possam ser utilizados como modelo experimental, de baixocusto éácil acesso, para estudos da interação embrião-B. abortus.
\end{abstract}

PALAVRAS-CHAVE: Reprodução animal, embrião, brucelose animal, modelos animais.

\section{ABSTRACT}

EVALUATION OF SUSCEPTIBILITY OF MOUSE ZYGOTES TO BRUCELLA ABORTUS FOR ESTABLISHMENT OF AN EXPERIMENTAL MODEL FOR PATHOGEN-EMBRYO INTERACTION STUDIES. The aim of this study was evaluate in-vitro the susceptibility of mouse zygotes to Brucella abortus, with the purpose of establishing an accessiblemodel for embryo-pathogeninteraction studies. The female mice (Swiss Webster) were superovulated and mated with fertile males of the same strain, and then the zygote retrieval was performed. The bacterial suspension was prepared at the moment of inoculation, and the dilution was $10^{6}$ brucellas $/ \mathrm{mL}$. The zygotes were divided into control and infected groups ( $30 \mathrm{~mL}$ of the bacterial suspension); after 24 and 96h their morphology and viability were analyzed. Morphological changes were not observed in the control group, but the infected one presented irregular blastomers, defective cleavage, granular cytoplasm with degenerative-like morphology. Thecleavage rates were $77.4 \%$ (control) and 59.2\% (infected) $\left(\chi^{2}\right.$ de $\left.0.001674 ; \mathrm{p}<0.05\right)$ after $24 \mathrm{~h}$, and after $96 \mathrm{~h} 14.5 \%$ (control) and $7 \%$ (infected) $\left(\chi^{2}\right.$ de $\left.0.141616 ; \mathrm{p}<0.05\right)$. According to the data, mice zygotes are susceptible to B.abortus in-vitro infection. Probably they could be used as an efficient and accessible experimental model for studies of embryo-pathogen interactions.

KEY WORDS: Embryos, animal brucelosis, animal reproduction, animal model.

\section{INTRODUÇÃO}

O advento de técnicas bem sucedidas para a criopreservação de embriões impulsionou a comercialização da transferência (TE) e da produção in vitro de embriões (PIV) (STRINGFELlowetal.,1986). Do ponto de vista epidemiológico, as novas tecnologias representam um desafio para o controle da transmissão de doenças, pois produzem novos ambientes e manipulação excessiva do material, possibilitando uma maior chance de contaminação e disseminação de patógenos (StringFellowet al., 2004). A maioria dos sistemas usados para produzir embriões por fertilização in vitro (FIV) requer meios complexos com algum tipo de soro ou células de suporte, que provêm um ambiente favorável para o desenvolvimento embrionário (D’ ANGElo et al., 2003a; GONÇALVES et al., 1997; KRISHER \& BAVISTER, 1998), mas que podem permitir 
com facilidade a introdução e manutenção de microrganismos no sistema (D'ANGELO et al., 2002; GALUPPO et al., 1998).

Em relação ao risco de transmissão de doenças por transferência de embriões produzidos in vivo ou in vitro, os resultados das pesquisas mostram que este risco é menor quando comparado com animais vivos (GuERIN et al., 1997). Entretanto, como muitas mudanças ocorreram em relação às tecnologias empregadas na manipulação dos embriões até o momento da transferência, o controle do status sanitário do embrião tornou-se mais complexo.

São de particular interesse os agentes infecciosos associados com tecidos ovarianos, tubáricos e uterinos, bem como contaminantes externos (STRINGFELlow, 1998). A tendência da Brucella abortus em se localizar no útero de bovinos levou à preocupação com a possibilidade de sua transmissão por procedimentos de reprodução animal. A Brucelose bovina é uma zoonose causada pela B. abortus (AgUiAR et al., 2001), possui distribuição mundial, acarretando severos prejuízos de ordem econômica (RAMIREzRomero, 1998; Rотн et al., 2003). Na espécie bovina, a sintomatologia da enfermidade está principalmente relacionada à esfera reprodutiva, levand o tanto fêmeas quanto machos a subfertilidade e/ou infertilidade (Aguiar et al., 2001; Del Fava et al., 2003; Radostitis et al., 2000).

Deve-se notar que, a maioria dos autores enfatiza que o risco de transmissão de $B$. abortus é mínimo quando se trata de embriões com zona pelúcida (ZP) intacta. Porém, com o desenvolvimento e uso comercial de tecnologias como a fecundação in vitro (FIV), a injeção intracitoplasmática de espermatozóide(ICSI), a clonagem e técnicas para criação de animais transgênicos, entre outras, podem ocorrer danos na estrutura da ZP (STRINGEFEllowetal.,2004). Certamente, essas técnicas provocam uma grande mudança no ambiente de PIV, o que possibilita oportunidades para a amplificação e disseminação de patógenos, como a $B$. abortus, anteriormente considerados sem risco de transmissão. A avaliação do potencial de dispersão de patógenos através das técnicas de PIV ainda não está completa, e precauções definitivas ainda não foram estabelecidas. Tendo isso em vista, o presente estudo teve como objetivos, avaliarinvitro, a sensibilidade de zigotos murinos a $B$. abortus cepa 1119.3 e estabelecer um modelo in vitro acessível e de baixo custo para o estudo de interações embriõespatógenos.

\section{MATERIAL E MÉTODOS}

Foram utilizados 50 camundongos (Musmusculus) Swiss Webster da colônia do biotério do Instituto
Biológico de São Paulo. Para o experimento foram utilizadas fêmeas púberes, nulíparas, entre 6 a 8 semanas de idade, acasaladas com machos inteiros da mesma linhagem e idade, após superestimulação ovariana.

Os hormônios utilizados para superestimulação ovariana foram a gonadotrofina coriônica eqüina (eCG/PMSG) e a gonadotrofina coriônica humana (hCG). Foram injetados, intraperitonealmente, por animal 0,2 mL (5UI) de cada hormônio. Inicialmente, as fêmeas receberam $0,2 \mathrm{~mL}$ de eCG/PMSG e após 46$48 \mathrm{~h}$ receberam $0,2 \mathrm{~mL}$ de hCG. Após a aplicação do hCG foram colocadas 2 fêmeas para cada macho para acasalamento. Dezoito horas após a aplicação do hCG, foi realizada a coleta dos zigotos (HoGAN et al., 1986).

A coleta dos zigotos teve início com o sacrifício das fêmeas, executado por deslocamento cervical, pois é um método rápido e indolor, além de não causar danos aos embriões (PAssos et al., 2002). Foi feita uma abertura na pele e peritônio para a coleta dos ovidutos. Os ovidutos foram mantidos aos pares, em gotas de $200 \mu \mathrm{L}$ de meio de lavagem tamponado até que todos os animais fossem sacrificados. Com o auxílio de uma lupa e duas agulhas $(16 \times 0,5 \mathrm{~mm})$, os ovidutos foram abertos, os zigotos foram coletados e rapidamente transportados para uma nova gota $(200 \mu \mathrm{L})$ de meio de lavagem. Os zigotos foram lavados por 30 segundos em solução de pronase a $0,5 \%$ a $37^{\circ} \mathrm{C}$, para total remoção das células do cúmulos. Em seguida, foram lavados em 3 gotas de meio de lavagem acrescido de $1 \%$ de soro fetal bovino (SFB) para inativação da pronase (HoGan et al., 1986).

Para a infecção foi utilizada a bactéria B. abortus cepa 1119.3, cultivada em condições de microaerofilia $\left(5 \% \mathrm{CO}_{2}\right.$ ) em meio de agar-bisulfito, a $37^{\circ} \mathrm{C}$. A suspensão de bactérias foi preparada no momento da inoculação, em solução salina estéril, na diluição de $10^{6}$ bactérias $/ \mathrm{mL}$.

Os zigotos foram separados em grupo controle e grupo infectado, os quais foram mantidos em gotas de $100 \mu \mathrm{L}$ de meio TCM 199 suplementado com $10 \%$ de SFB e $0,2 \%$ de piruvato de sódio, sob óleo mineral estéril. A cultura foi mantida em estufa a $5 \%$ de $\mathrm{CO}_{2}$, $90 \%$ de umidadee $37^{\circ} \mathrm{C}$. A infecção foi feita com $30 \mathrm{~mL}$ da suspensão de bactérias. Para padronização do experimento foi adicionado às gotas do grupo controle $30 \mu \mathrm{L}$ de solução salina estéril. Após $24 \mathrm{~h}$ e $96 \mathrm{~h}$ de infecção os zigotos foram avaliados quanto a sua morfologia e viabilidade. A análise da morfologia foi realizada sob microscópio óptico invertidoe a análise da viabilidade foi realizada através da avaliação da taxa de clivagem dos embriões, na presença ou ausência do patógeno. Para essas análises foi utilizado um microscópio, e os zigotos foram observados em um aumento de 100X. 


\section{RESULTADOS}

\section{Análise da morfologia embrionária}

No grupo controle não foram verificadas alterações morfológicas após 24 ou 96h de cultura (Figs. 1 e 4). Já no grupo infectado, foi possível verificar a presença de alterações como blastômeros assimétricos (Figs. 2, 3, 5 e 6), falha de divisão (Fig. $3)$, citoplasma com granulação e aspecto degenerativo(Figs. 2,3 e 6), em ambos os períodos de incubação.

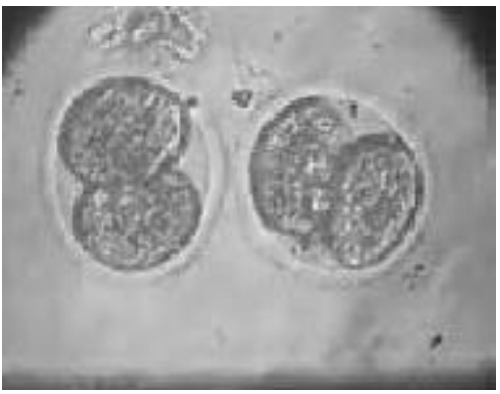

Fig. 1 - Embriões do grupo controle após 24h deincubação(100x,2X zoom)

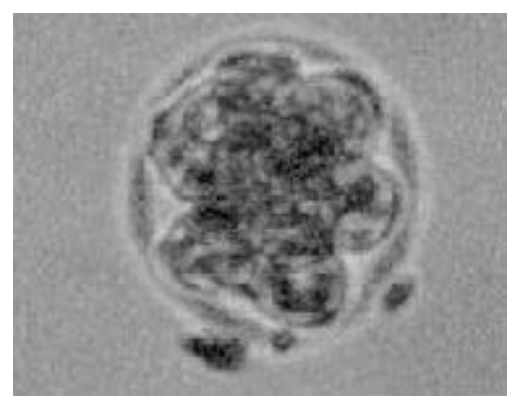

Fig. 4-Mórula do grupo controleapós 96h de incubação (100x, 10X zoom)

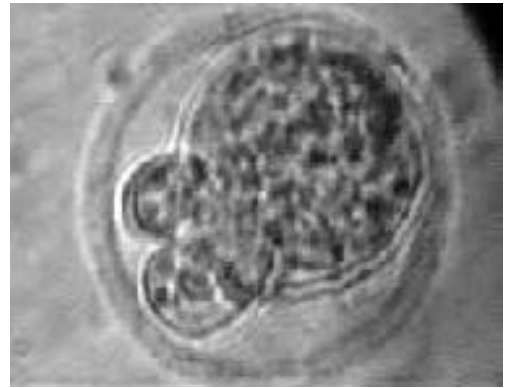

Fig. 2 -Embrião após 24 h de infecção com B. abortus (100x, 10X zoom)

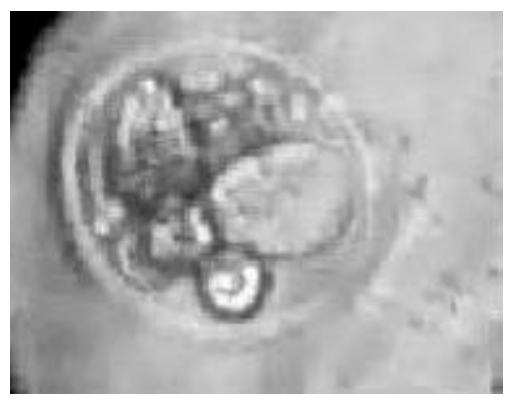

Fig. 5 - Mórula após 96h de infecção com B. abortus (100x, 10X zoom)

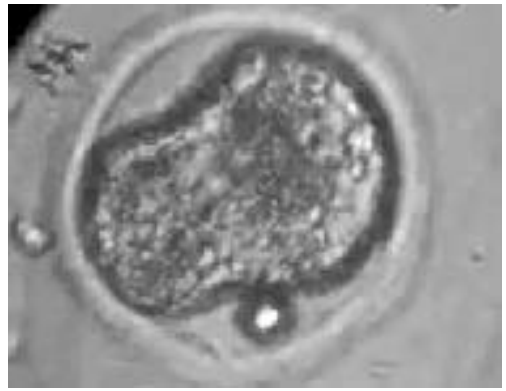

Fig. 3 - Embrião após 24h de infecção com B. abortus (100x, 10X zoom)

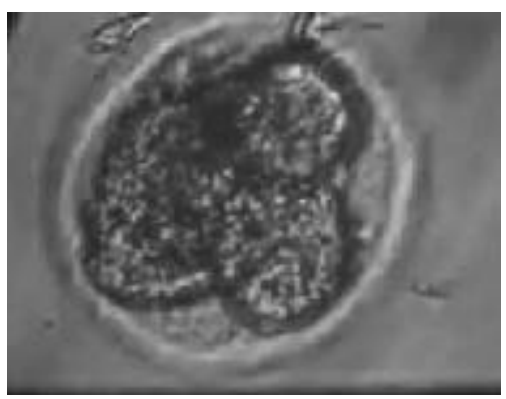

Fig. 6 - Mórula após 96h de infecção com B. abortus (100x, 15X zoom)

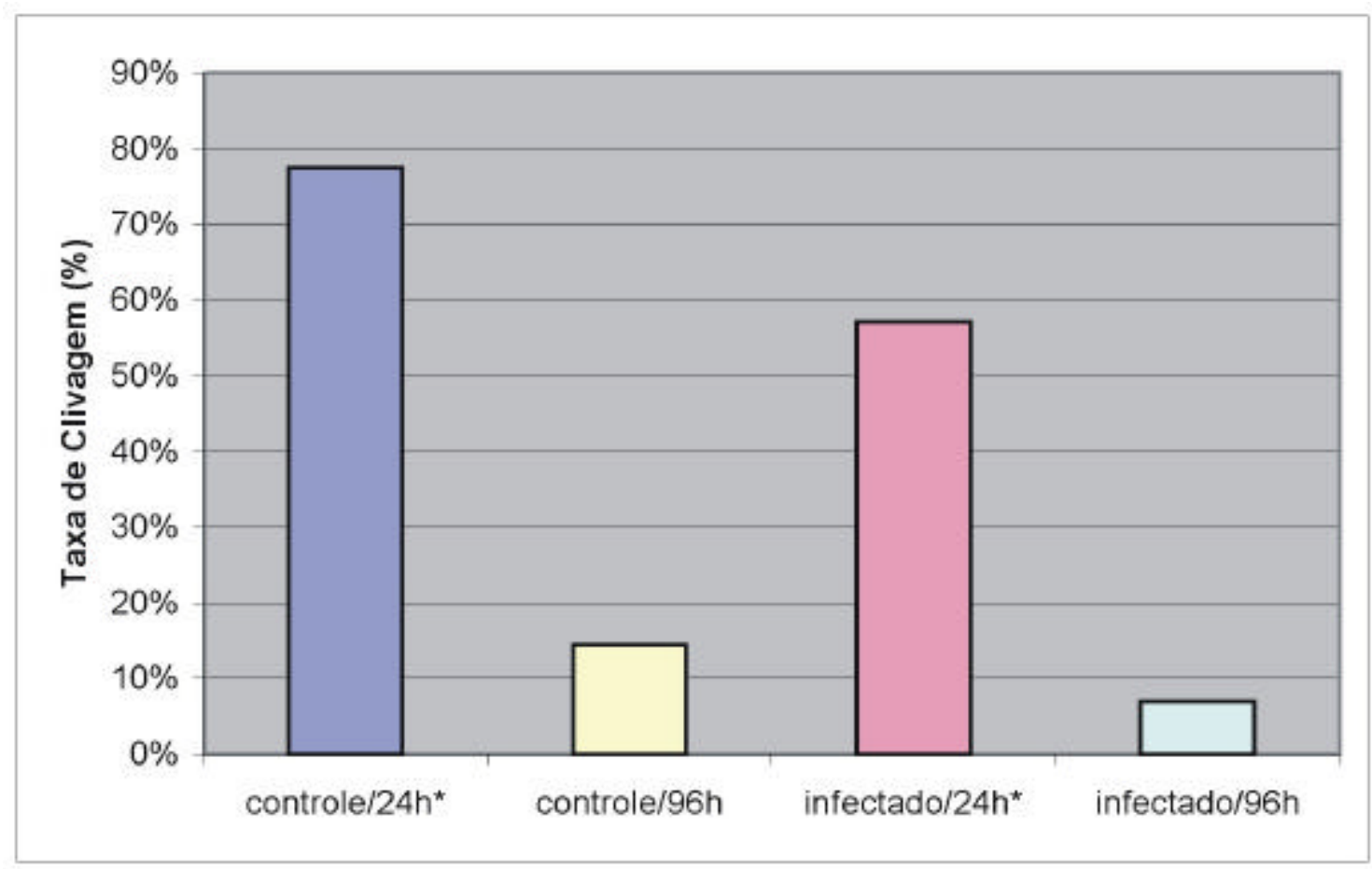

Fig.7 - Taxa de clivagem de zigotos murinos após 24 e 96 h da infecção com B. abortus nos grupos controleeinfectado $\left({ }^{*} \mathrm{p}<0,05\right)$ 


\section{Análise da viabilidade embrionária}

Após 24h de exposição dos zigotos murinos à $B$. abortus foi verificada a taxa de clivagem que, no grupo controle, foi de $77,4 \%(89 / 115)$ e a do grupo infectado foi de 59,2\% (90/152). Pode-se verificar que a taxa de clivagem do grupo infectado apresentou-se significativamente menor $\left(\chi^{2}\right.$ de 0,$\left.001674 ; p<0,05\right)$ do que a do grupo controle. Após 96 horas de infecção, o grupo controle apresentou 14,5\% (9/62) de embriões com mais de duas células, enquanto que o grupoinfectado apresentou apenas $7 \%$ (6/85), entretanto, estatisticamente a diferença entre esses dois grupos não foi significativa $\left(\chi^{2}\right.$ de 0,$\left.141616 ; p<0,05\right)$ (Fig.7).

\section{DISCUSSÃO}

A cada nova tecnologia que surge na área de reprodução animal ocorre uma mudança ambiental capaz de influenciar o potencial de dispersão de patógenos em um rebanho e, portanto, pode-se considerar que a qualidade da manipulação dos gametas e embriões é um importante fator relacionado a possibilidade de transmissão de doenças para a nova população gerada (STRINGEFelLow etal., 2004). O resultado final do processo dependerá do estabelecimento de controles adequados, assim como, da qualidade técnica e ética dos profissionais envolvidos.

As altas concentrações de B. abortus utilizadas nas suspensões experimentais foram utilizadas para promover o máximo de oportunidade para aderência ou entrada do microrganismo nos embriões (Stringefellow et al., 1986). Mallek et al. (1984) trabalhando com B. abortus utilizaram suspensões de até $10^{5}$ brucellas/mL para infecção de embriões bovinos e de camundongosin vitro. STRINGFELLOWet al. (1986) trabalharam com uma suspensão de $10^{6}$ ufc/mL de B. abortus para infecção de embriões bovinos in vitro. BIELANSKY et al. (1997) utilizaram em um estudo realizado com Campylobacter fetus, para infecção de amostras de sêmen, uma concentração de $10^{8} \mathrm{ufc} / \mathrm{mL}$ da bactéria. Tendo como base esses estudos, nesse trabalho foi utilizada uma suspensão com $10^{6}$ brucellas/mL para a infecção dos zigotos murinos.

A escolha do camundongo como modelo experimental foi baseada em trabalhos previamente publicados (D'ANGelo et al., 2003d; MAllek et al., 1984). MALLEK et al., (1984) utilizaram embriões de camundongo como modelo para oestudo das conseqüências da contaminaçãoinvitro desses embriões por B.abortus. Utilizaram embriões com ZP intacta no estádio de mórula, os quais foram expostos a concentrações sucessivas de Brucella, partindo de $10^{2}$ até $10^{5}$ brucellas/mL. Após $24 \mathrm{~h}$ de infecção, pode ser verificada a ocorrência de alterações no desenvolvimento dos embriões, sugerindo sua sensibilidade à $B$. abortus (MALLEK et al., 1984). Além da suscetibilidade ao agente, sabe-se que os embriões de camundongo são sensíveis a diferentes patógenos, são de fácil acesso e baixo custo, o que os torna um excelente modelo para estudos de interação embrião-patógeno (D'Angelo et al., 2001; Galuppo \& D'Angelo, 1999).

Nesse trabalho, a avaliação da sensibilidade dos zigotos ao patógeno foi realizada pela análise da sua morfologia e viabilidade (através da taxa de clivagem), após exposição à B. abortus por 24 e $96 \mathrm{~h}$. Quanto à morfologia, no grupo controle, não foram verificadas alterações após 24 ou 96h decultura (Figs. 1 e 4). Jáno grupo infectado foi possível verificar a presença de alterações, como blastômeros assimétricos, falhas na divisão e citoplasma com granulação e aspecto degenerativo em ambos os grupos (24h e 96h) (Figs.2, $3,5 \mathrm{e} 6)$. Apenas na zona pelúcida não foram verificadas alterações visíveis ao microscópio óptico (Figs. 1 a 6). Em relação à taxa de clivagem, pode-se verificar que, no grupo infectado, esta se apresentou significativamente menor $(59,2 \%)\left(\chi^{2}\right.$ de 0,$\left.001674 ; p<0,05\right)$ do que a encontrada para o grupo controle $(77,4 \%)$ após $24 \mathrm{~h}$ decultura (Fig.7). Enquanto que após 96h de infecção não foi obtida uma diferença significativa nessa taxa $\left(\chi^{2}\right.$ de 0,141616; $\left.p<0,05\right)$ (Fig. 7). Os resultados estão de acordo com os descritos por D' ANGelo et al. (2003) onde foi possível verificar que zigotos murinos expostos in vitro à $B$. abortus apresentaram alterações morfológicas logo após as primeiras $24 \mathrm{~h}$ de infecção. Esses autores verificaram bloqueio no desenvolvimento dos embriões infectados no estádio de 2 células, assim como granulação e retração do citoplasma dos blastômeros, seguida de degeneração citoplasmática. STRINGFELLOW et al. (1986) observaram que a cultura de embriões na presença de B. abortus por até18h não promovenenhum efeito prejudicial ao seu desenvolvimento, porém após esse período, os embriões começaram a apresentar sinais de degeneração. Sabe-se que as condições de cultivo de embriões precisam mimetizar ao máximo o ambiente encontrado naturalmente no oviduto e útero e, apesar de toda a tecnologia empregada para o desenvolvimento de melhorias desse sistema, a condição estática do meio fornece um ambiente totalmente diferente daquele encontrado in vivo, onde o suprimento de nutrientes e gases é dinamicamente alterado (KruIP et al., 2000). Segundo StRINGFellow et al. (1986) essas observações suportam a hipótese de que, provavelmente, as alterações morfológicas e a redução de viabilidade dos embriões na presença de $B$. abortus após o período de $18 \mathrm{~h}$ são causadas pelas alterações ocorridas no meio de cultura devido à proliferação das bactérias, e não por seu efeito direto nos embriões(STRINGFELLOW et al., 1986). 
Considerando os resultados apresentados, podese concluir que os zigotos murinos são sensíveis à $B$. abortus após exposição in vitro, uma vez que foram verificadas alterações na sua morfologia e desenvolvimento após a infecção. Provavelmente os zigotos murinos podem ser utilizados como modelo experimental, de baixo custo e fácil acesso, para estudos da interação embrião-B. abortus. Entretanto, a análise geral dos resultados obtidos no presente trabalho carece de uma ponderação fundamental quanto à possibilidade de extrapolar observações feitas em sistemas in vitro para sistemas in vivo. Entre outros fatores, a presença de sistema imune, a organização tecidual e os mecanismos de excreção de substâncias, tornam o sistema in vivo extremamente complexo, exigindo cautela para extrapolar observações feitasin vitro (D'ANGELO, 1998).

\section{AGRADECIMENTOS}

À Cultilab ${ }^{\circledR}$ (Campinas-SP) pela colaboração à realização deste trabalho.

\section{REFERENCIAS}

Aguiar, D.M.; Rbeiro, M.G.; Brito, A.F.; PessoA, V.M. Soroaglutinação, sêmen plasma aglutinação e exame andrológico no diagnóstico da Brucelose em machos bovinos. Arquivos do Instituto Biológico, SãoPaulo, v.68, n.2, p.103-105, 2001.

Bielanski, A. A review on disease transmission studies in relationship to production of embryos by in vitro fertilization and to related new reproductive technologies. Biotechnologies Advances, v.15, n.3/4, p.633-656, 1997.

D'ANGELO, M. Interação do herpesvírus bovino tipo 1 (BHV-1) com oócitos bovinos maturados in vitro. 1998. 52p. Tese (Doutorado) - Instituto de Ciências Biomédicas, Universidade de São Paulo, São Paulo, 1998.

D'Angelo, M.; Galuppo, A.G.; Gonçalves, R.F. Estudo comparativo da sensibilidade de culturas primárias de células epiteliais de oviduto bovinoe murino ao BHV1. Arquivos do Instituto Biológico, São Paulo, v.69, n.4, p.19-22, 2002.

D'Angelo, M.; Mello, M.R.B.; Galuppo, A.G.; Visintin, J.A. Estudo comparativo do desenvolvimento de embriões murinos em diferentes sistemas de co-cultivo como modelo experimental em estudos de fecundação in vitro. Arquivos do Instituto Biológico, São Paulo, v.68, p.129, 2001. Suplemento. Trabalho apresentado à Reunião Anual do Instituto Biológico, 14., 2001. Resumos

D’ Angelo, M.; Silva, S.A.C.M.;SEnedezi, M.L.P.; GonÇAlveS, R.F.; Galuppo, A.G.; BarRa, S.H.C.; Melo, G.M.; Zerio, N.M.C. Morphological evaluation of mice zygotes experimentally infected by Brucella abortus. Biology of Reproduction, v.68, p.163, 2003d. Supplement 1 . Traba- lho apresentado à Annual Meeting of the Society for the Study of Reproduction, 36., 2003, Cincinnati. Resumo n.124.

Del Fava, C.; Arcaro, J.R.P.; Pozzi, C.R.; Arcaro Junior, J.; Fagundes, H.; Pituco, E.M.; De Stefano, E.; OKuda, L.H.; VASCONCELLOS, S.A. Manejo sanitário para o controle de doenças da reprodução em um sistema leiteiro de produção semi-intensivo. ArquivosdoInstitutoBiológico, São Paulo, v.70, n.1, p.25-33, 2003.

Galuppo, A.G. \& D'Angelo, M. Sensibilidade de embriões murinos ao vírus da rinotraqueíte infecciosa bovina. Arquivos da Faculdade de Medicina Veterinária UFRS, v.27, n.1, p.236, 1999. Suplemento 27. Trabalho apresentado à Reunião Anual da Sociedade Brasileira de Transferência de Embriões, 14., 1999, Campos do Jordão.

Galuppo, A.G.; D'Angelo, M.; GonçAlves, R.F. Estudo comparativo da sensibilidade de culturas primárias de células epiteliais de oviduto bovino e murino ao vírus da rinotraqueíte infecciosa bovina. Arquivos do Instituto Biológico, v.65, p.99, 1998. Suplemento. Trabalho apresentado à Reunião Anual do Instituto Biológico, 11., 1998, São Paulo. Resumo n.150.

Gonçalves, R.F.; D’Angelo, M.; Galuppo, A.G. Uso da microscopia eletrônica de varredura na avaliação morfológica de células epiteliais de oviduto bovino in vitro. Arquivos do Instituto Biológico, v.64, p.150, 1997. Suplemento. Trabalho apresentado à Reunião Anual do Instituto Biológico, 10., 1997, São Paulo. Resumo n. 60 .

Guerin, B.; Nibart, M.; Marquant-Le Guienne, B.; Humblot, P.Sanitary risks related to embryo transfer in domestic species. Theriogenology, v.47, p.33-42, 1997.

Hogan, B.; Constantini, F.; Lacy, E. Developmental genetics and embryology of the mouse: past, present, and future. In:_. Manipulating the mouse embryo: a laboratory manual. New York: Cold Spring Harbor Laboratory, 1986. p.12-14.

KRISHER, R. L. \& BAVISTER, B. D. Responses of oocytes and embryos to the culture environment Theriogenology, v.49, p.103-114, 1998.

KRUIP, T.A.M.; BeVERS, M.M.; KEMP, B. Environment of oocyte and embryo determines health of IVP offspring. Theriogenology, v.53, p.611-618, 2000.

Mallek, Z.; Guerin, B.; Nibart, M.; Parez, M.; Thibier, M. Conséquences de la contamination in vitro des embryons de souris et de vaches par B. abortus. Bulletin de l'Académie Veterinari de France, v.57, p.479490, 1984.

Passos, L.A.C.; Guaraldo, A.M.A.; Alves, D.P.; Pires, L.A.; SANTANA, T.M.; DinI, T.H.C. Criopreservação de embriões murinos em biotérios. In: ANDRADE, A.; P INTO, S.C.; Qrverra, R.S. Animais de laboratório criação e experimentação. Rio de Janeiro: Fiocruz. 2002. p.225245.

Radostitis, O.M.; Gay, C.C.; BloOd, D.C.; HinchclifF, K.W. Diseases caused by Brucella spp. Veterinary Medicine, p. 867-891, 2000.

RAMIREZ-ROMERO, R. Is B. abortus a facultative intracellular pathogen with mitochondria-like activity? Medical hypotheses, v.51, p.41-45, 1998. 
Roth, F.;Zinsstag, J.; OrKHON, D.; C HIMED-Ochir, G.; Hutton, G.; CovISI,O;; CARRIN,G.;OTTE, J. Human health benefits from livestock vaccination for brucellosis: casestudy. Bulletinof the World Health Organization, v.12, n.B1, p.867-875, 2003.

Stringfellow, D.A. \& Givens, M.D. Infectious agents in bovine embryo production: hazards and solutions. Theriogenology, v.53, p.85-94, 2000.

Stringfellow, D.A.; Givens, M.D.; W ALDROP, J.G. Biosecurity issues associated with current and emerging embryo technologies. Reproduction, Fertility and Development, v.16, p.93-102, 2004.

StringFellow, D.A..; Wolfe, D.F.; LAUERMAN, L.H..; SPARLING, P.H. Resistance of preimplantation bovine embryos to infection with B.abortus. American Journal of Veterinary Research, v.47, n.9, p.1924-1927, 1986.
StRINGEFelLow, D.A. Recomendações para o manuseio sanitário de embriões obtidos in vivo. In:STRINGEFELLOW, D.A. \& SEIDEL, S.M. (Eds.). Manual da Sociedade Internacional de Transferência de Embriões. 3. ed. Jaboticabal: SBTE, 1998. p.83-96.

ThiBIER, M. Identified and unidentified challenges for reproductive biotechnologies regarding infectious diseases in animal and public health. Theriogenology, v.56, p.1465-1481, 2001.

Recebido em 24/4/06

Aceito em 1/7/06 